\title{
Achromobacter marplatensis sp. nov., isolated from a pentachlorophenol-contaminated soil
}

\author{
Margarita Gomila, ${ }^{1}$ Ludmila Tvrzová, ${ }^{2}$ Andrea Teshim, ${ }^{2}$ Ivo Sedláček, ${ }^{3}$ \\ Narjol González-Escalona, ${ }^{4}$ Zbyněk Zdráhal, ${ }^{5}$ Ondrej Šedo, ${ }^{5}$ Jorge \\ Froilán González, ${ }^{6}$ Antonio Bennasar, ${ }^{1,7}$ Edward R. B. Moore, ${ }^{8,9}$ \\ Jorge Lalucat ${ }^{1}$ and Silvia E. Murialdo ${ }^{6}$
}

Correspondence Margarita Gomila marga.gomila@uib.es
Pentachlorophenol (PCP) was generally believed to be resistant to environmental degradation until numerous investigators reported the isolation of fungi and bacteria able to degrade it (Litchfield \& Rao, 1998; Tiirola et al., 2002). Although many bacteria are able to metabolize

Abbreviations: CFA, cellular fatty acid; FAME, fatty acid methyl ester; $\mathrm{PCP}$, pentachlorophenol.

The GenBank/EMBL/DDBJ accession number for the 16S rRNA gene sequence of strain $B 2^{\top}$ is EU150134. The accession numbers for the other 16S rRNA gene sequences determined in this study are FM999731-FM999735.

Four supplementary tables and a supplementary figure are available with the online version of this paper. organic pollutants, very few strains have the capability to mineralize high concentrations of PCP in contaminated wastewaters (Lee et al., 1998). With the objective of finding novel strains better able to degrade PCP, strain $\mathrm{B} 2^{\mathrm{T}}$ was isolated from a PCP-contaminated site in Argentina (Murialdo et al., 2003). Initial analyses indicated that the isolate could be a strain of Alcaligenes or Bordetella, but further taxonomic characterization of strain $\mathrm{B} 2^{\mathrm{T}}$ led to its recognition as a novel member of the genus Achromobacter.

The genera Alcaligenes and Achromobacter belong to the class Betaproteobacteria, grouped together in the family Alcaligenaceae (Busse \& Auling, 2005). The taxonomy of the genera Alcaligenes and Achromobacter is closely 
intertwined; several Alcaligenes species were reclassified in Achromobacter by Yabuuchi et al. (1998). The genus Achromobacter now contains six species: Achromobacter denitrificans, A. insolitus, A. piechaudii, A. ruhlandii, A. spanius and $A$. xylosoxidans (the type species). These species have been isolated from a range of different sources, mainly from water and soil, but also from clinical samples. A. xylosoxidans is widespread in oligotrophic aquatic niches and is an opportunistic human pathogen, able to cause a variety of infections (Busse \& Auling, 2005). A. denitrificans strains are found in soil but are also occasionally found in human clinical samples (Busse \& Auling, 2005; Coenye et al., 2003b). A. piechaudii has been isolated from soil and human clinical samples, including blood (Kiredjian et al., 1986). A. ruhlandii is considered to be a soil inhabitant and is not known to be associated with human clinical conditions (Busse \& Auling, 2005) and A. insolitus and A. spanius were isolated from a leg wound and blood samples, respectively (Coenye et al., 2003a).

We performed a polyphasic taxonomic study to elucidate the taxonomic position of strain $\mathrm{B}^{\mathrm{T}}$, isolated from soil by selective enrichment with PCP. On the basis of comparative 16S rRNA gene sequence analysis, it was observed to cluster most closely with species of the genus Achromobacter. Phenotypic data, including chemotaxonomic characteristics, ribotyping and DNA-DNA hybridization suggest that strain $\mathrm{B} 2^{\mathrm{T}}$ represents a novel species in the genus Achromobacter.

Strain $\mathrm{B} 2^{\mathrm{T}}$ was isolated in mineral salts base (MS) medium supplemented with PCP as sole carbon source by enrichment of a sample of soil containing PCP collected near a wastewater discharge site. The initial PCP concentration was $5 \mathrm{mg} \mathrm{l}^{-1}$ and the concentration was increased in subsequent enrichment subcultures to $100 \mathrm{mg} \mathrm{l}^{-1}$, as described previously (Murialdo et al., 2003). Strain $\mathrm{B} 2^{\mathrm{T}}$ was able to metabolize PCP alone or in the presence of glucose as co-substrate (Murialdo et al., 2003).

Type strains of all species of the genus Achromobacter were included in this study: A. denitrificans CCM $3427^{\mathrm{T}}$ and CCUG $407^{\mathrm{T}}$, A. insolitus CCM $7182^{\mathrm{T}}$ and CCUG $47057^{\mathrm{T}}$, A. piechaudii CCM $2986^{\mathrm{T}}$ and CCUG $724^{\mathrm{T}}$, A. ruhlandii CCM $7494^{\mathrm{T}}$ and CCUG $57103^{\mathrm{T}}$, A. spanius CCM $7183^{\mathrm{T}}$ and CCUG $47062^{\mathrm{T}}$ and A. xylosoxidans CCM $2741^{\mathrm{T}}$ and CCUG $56438^{\mathrm{T}}$. These strains were cultivated on nutrient agar (Merck) unless stated otherwise and incubated for 23 days at $37{ }^{\circ} \mathrm{C}$, except for strains of $A$. denitrificans and $A$. ruhlandii, which were incubated at $30{ }^{\circ} \mathrm{C}$.

The 16S rRNA genes of all strains employed in this study were amplified by PCR using primers 16F27 and 16R1492 and sequenced as described previously (Gomila et al., 2005). PCR products were purified with Microcon centrifugal filter devices (Microcon-Millipore) according to the manufacturer's instructions. Sequencing reactions were carried out using the ABI Prism Big Dye Terminator version 3.1 cycle sequencing kit and the sequences were read with an automatic sequence analyser (ABI Prism 3730
DNA sequencer; Applied Biosystems). Nearly full-length gene sequences (1302 positions) were aligned with reference sequences of the closest relatives, retrieved using the BLAST analysis tool from the NCBI nucleotide sequence database (Altschul et al., 1990). Sequences were aligned using a hierarchical method for multiple alignments implemented in the CLUSTAL_X program (Thompson et al., 1997). Automatically aligned sequences were edited manually. Similarities and evolutionary distances were calculated with programs contained in PHYLIP (Felsenstein, 1989). Gene distances were calculated from nucleotide sequences by the Jukes-Cantor method (Jukes \& Cantor, 1969) and dendrograms were generated by the neighbourjoining method. Alternative analyses of the sequence data were carried out using different algorithms (maximumlikelihood, parsimony and Fitch-Margoliash) and all analyses supported the derived phylogenetic position of strain $\mathrm{B}^{\mathrm{T}}$ within the genus Achromobacter. Bootstrap analysis of 1000 replications was performed in order to assess the reliability of the dendrogram branching order. Topologies of the trees were visualized with the TreeView program (Page, 1996). We found that the published sequence data for A. denitrificans LMG $1231^{\mathrm{T}}$ (M22509), A. piechaudii ATCC $45552^{\mathrm{T}}$ (AB01041) and A. xylosoxidans LMG $1863^{\mathrm{T}}$ (D88005) included a number of undetermined positions and possible erroneous gaps. Since the $16 \mathrm{~S}$ rRNA gene sequences of Achromobacter species have high levels of similarity to one another, exclusion of these undetermined or ambiguous positions could affect the elucidation of interspecies relationships. Therefore, the $16 \mathrm{~S}$ rRNA gene sequences for the type strains of the other Achromobacter species were determined, including those species whose sequences were already available. We used the new versions of the sequences, containing no ambiguities, for the phylogenetic analyses. The 16S rRNA gene sequence similarity between $\mathrm{B}^{\mathrm{T}}$ and the type strains of all other Achromobacter species was greater than $99 \%$. The highest similarity observed was $99.8 \%$, with A. piechaudii CCM $2986^{\mathrm{T}}$ and A. spanius CCM $7183^{\mathrm{T}}$ (A. piechaudii CCM $2986^{\mathrm{T}}$ and A. spanius CCM $7183^{\mathrm{T}}$ showed $100 \%$ similarity in their $16 \mathrm{~S}$ rRNA gene sequences). The neighbour-joining tree and the distance matrix are given in Fig. 1 and in Supplementary Table S1 (available in IJSEM Online), respectively.

Genomic DNA-DNA hybridizations were performed, in duplicate, using a non-radioactive method as described by Ziemke et al. (1998). Genomic DNA was isolated according to the method of Marmur (1961). Reference DNAs of strain $\mathrm{B} 2^{\mathrm{T}}$, A. piechaudii CCUG $724^{\mathrm{T}}$, A. spanius CCM $7183^{\mathrm{T}}$ and A. xylosoxidans CCUG $56438^{\mathrm{T}}$ were doublelabelled with DIG-11-dUTP and biotin-16-dUTP using a nick translation kit (Roche). Labelled DNA was hybridized separately with DNAs from strain $\mathrm{B} 2^{\mathrm{T}}$, A. denitrificans CCM $3427^{\mathrm{T}}$, A. insolitus CCM $7182^{\mathrm{T}}$, A. piechaudii CCM $2986^{\mathrm{T}}$, A. spanius CCM $7183^{\mathrm{T}}$, A. ruhlandii CCUG $57103^{\mathrm{T}}$ and A. xylosoxidans CCM $2741^{\mathrm{T}}$. The levels of DNA-DNA relatedness of strain $\mathrm{B}^{\mathrm{T}}$ with the other strains were, in all 


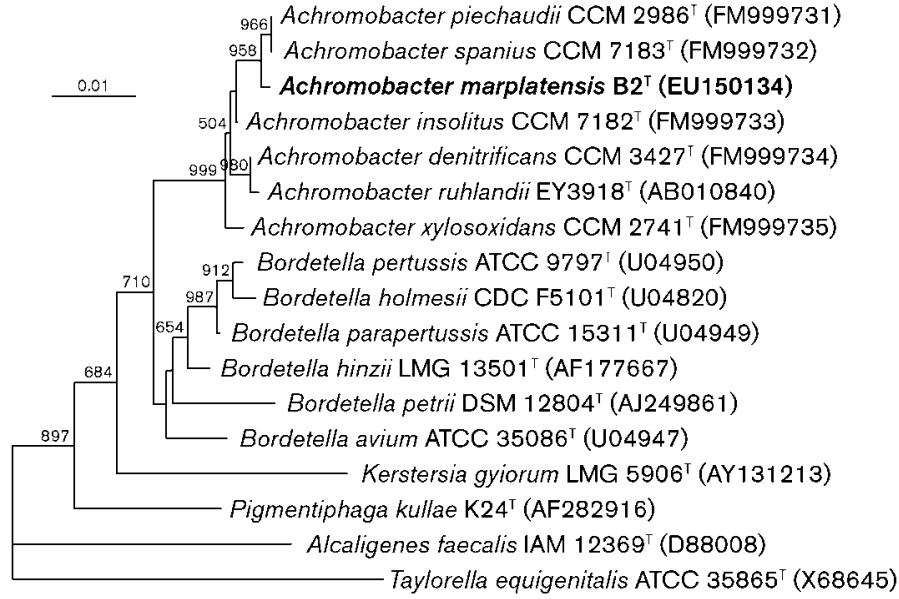

Fig. 1. Neighbour-joining tree showing derived phylogenetic relationships among strain $B 2^{\top}$ and type strains of the genus Achromobacter, based on 16S rRNA gene sequence comparisons. Numbers at branch nodes are bootstrap values from 1000 replicates. Bar, 1 substitution per 100 nucleotide positions. cases, lower than 56\% (Supplementary Table S2), confirming that strain $\mathrm{B} 2^{\mathrm{T}}$ was genomically distinct from the type strains of all species within the genus.

Strain $\mathrm{B} 2^{\mathrm{T}}$ is a motile, rod-shaped ( $1 \mu \mathrm{m}$ long), Gramnegative bacterium (Supplementary Fig. S1). Phenotypic analyses (API 20 NE, API ZYM and Biotype 100) were carried out to determine the characteristic profile for assimilation of organic compounds as sole carbon sources, according to the manufacturer's recommendations (bioMérieux). Inocula were taken from cultures grown for $16-20 \mathrm{~h}$ at $35{ }^{\circ} \mathrm{C}$ on nutrient agar. Conventional phenotypic tests were done according to Barrow \& Feltham (1993). The results showed that strain $\mathrm{B} 2^{\mathrm{T}}$ was able to assimilate phenylacetate, citrate and malate and showed weak growth with gluconate. It was also capable of nitrate and nitrite reduction, but showed a negative reaction in the Voges-Proskauer test. It was not capable of hydrolysis of aesculin or production of acid and $\mathrm{H}_{2} \mathrm{~S}$ from triple-sugariron agar. The inabilities to use D-glucose, adipate, caprate and D-gluconate as carbon sources for growth were physiological characteristics that differentiate $\mathrm{B} 2^{\mathrm{T}}$ from the other Achromobacter species (Table 1). The strain demonstrated oxidase, leucine arylamidase, alkaline and acid phosphatase, phosphoamidase and catalase activities, with few differences being observed between Achromobacter species for these tests (Supplementary Table S3).

Antibiotic resistance to kanamycin, amoxicillin, ampicillin and carbenicillin was tested by two different tests. The first test employed Luria-Bertani plates supplemented with 30 or $50 \mu \mathrm{g}$ antibiotic $\mathrm{ml}^{-1}$. For the second test, antibiotic susceptibility discs $(500 \mu \mathrm{g})$ were placed on MuellerHinton agar. Strains were inoculated onto the medium and grown for $20-48 \mathrm{~h}$ at $35{ }^{\circ} \mathrm{C}$. The presence of growth in the first test and the absence of an inhibition halo in the second test were assessed. Strain $\mathrm{B} 2^{\mathrm{T}}$ was observed to be resistant to $30 \mu \mathrm{g}$ kanamycin $\mathrm{ml}^{-1}$ and sensitive to amoxicillin, ampicillin and carbenicillin at this concentration.

Growth was tested on nutrient agar plates for 24-48 h at 4, $15,20,30,37,40$ and $42{ }^{\circ} \mathrm{C}$. Strain $\mathrm{B} 2^{\mathrm{T}}$ was able to grow at
15,20 and $40{ }^{\circ} \mathrm{C}$ but not at 4 or at $42{ }^{\circ} \mathrm{C}$, nor in the presence of $6.5 \% \mathrm{NaCl}$ (Table 1). Growth was observed on MacConkey agar.

The relative amounts of cellular fatty acids (CFAs) can be useful for the chemotaxonomic characterization of Gramnegative, non-fermenting taxa. Cellular fatty acid methyl ester (FAME) profiles were determined using GC and a standardized protocol similar to that of the MIDI Sherlock MIS system (http://www.ccug.se/pages/cfanew.pdf). Prior to CFA extraction, strains were grown and harvested under the same conditions, using blood agar as the cultivation medium. The relative amounts of each CFA were expressed as percentages of the total fatty acids. Only CFAs with chain lengths of 9 to 18 carbon atoms were analysed. Predominant fatty acids observed in strain $B 2^{\mathrm{T}}$ were $\mathrm{C}_{16: 0}$, $\mathrm{C}_{16: 1} \omega 7 c$ and $\mathrm{C}_{17: 0}$ cyclo. Detailed fatty acid compositions are indicated in Table 2. The CFA profile of strain $B 2^{\mathrm{T}}$ conformed to the general profile of Achromobacter species; only slight differences could be established in comparison with other type strains of the genus (e.g. in $\mathrm{C}_{14: 0} 2-\mathrm{OH}$ ).

Matrix-assisted laser desorption ionization time-of-flight mass spectrometry (MALDI-TOF MS) was used for additional differentiation and characterization of strain $\mathrm{B} 2^{\mathrm{T}}$ with respect to the type strains of other species of the genus Achromobacter. Cells for MALDI-TOF MS were harvested from $24 \mathrm{~h}$ cultures, grown as a second subculture at $30{ }^{\circ} \mathrm{C}$ on tryptone soy agar (Oxoid). The cells were suspended in $0.5 \mathrm{ml}$ acetonitrile/water $(1: 1)$. Bacterial suspensions were mixed with MALDI matrix solution in a ratio of $1: 4(\mathrm{v} / \mathrm{v})$ and $0.6 \mu \mathrm{l}$ aliquots of the mixture were pipetted onto three individual spots of a stainless-steel MALDI target. As a MALDI matrix, sDHB (90\% 2,5dihydroxybenzoic acid and 10\% 2-hydroxy-5-methoxybenzoic acid, $20 \mathrm{mg} \mathrm{ml}^{-1}$ in $20 \%$ acetonitrile and $1 \%$ trifluoroacetic acid) was used (Tvrzová et al., 2006). MALDI-TOF MS measurements were carried out using a Reflex IV instrument (Bruker Daltonik) operated in linear positive mode with $20 \mathrm{kV}$ acceleration voltage. Mass spectra were accumulated in the mass range $4-20 \mathrm{kDa}$ 
Table 1. Phenotypic characteristics of strain $\mathrm{B} 2^{\top}$ and type strains of Achromobacter species

Strains: 1, strain B2 ${ }^{\mathrm{T}}$; 2, A. denitrificans CCM $3427^{\mathrm{T}}$; 3, A. insolitus CCM 7182 $;$;, A. piechaudii CCM 2986 ${ }^{\mathrm{T}}$; 5 , A. ruhlandii CCM $7494^{\mathrm{T}} ; 6$, A. spanius CCM $7183^{\mathrm{T}} ; 7$, A. xylosoxidans CCM $2741^{\mathrm{T}}$. +, Positive; -, negative; w, weak; ND, not determined. These data were obtained in this study. Data in parentheses give information on intraspecific variability as follows and were taken from Busse \& Auling (2005) and Coenye et al. (2003b): ,$+ \geqslant 90 \%$ strains positive; [+], $\geqslant 80 \%$ strains positive; $d, 11-79 \%$ of strains positive;,$- \leqslant 10 \%$ of strains positive. No information on strain variability has been reported for A. insolitus or A. spanius. All strains are negative for aesculin hydrolysis, DNase, urease, lysine decarboxylase, ornithine decarboxylase and $\beta$-galactosidase and positive for nitrate reduction. All strains grow with L-malate, but not with L-arabinose, D-mannitol, $N$-acetylglucosamine or maltose.

\begin{tabular}{|c|c|c|c|c|c|c|c|}
\hline Characteristic & 1 & 2 & 3 & 4 & 5 & 6 & 7 \\
\hline \multicolumn{8}{|l|}{ Growth at: } \\
\hline $22{ }^{\circ} \mathrm{C}$ & + & ND & - & + & + & - & ND \\
\hline \multicolumn{8}{|l|}{ Hydrolysis of: } \\
\hline Gelatin, starch & - & - & - & - & - & - & $-*$ \\
\hline Tween 80 & - & - & - & - & - & - & $-{ }^{*}$ \\
\hline D-Glucose & - & $-(-)$ & - & - & $+(+)$ & - & $+(+)$ \\
\hline D-Gluconate & $\mathrm{w}$ & $-([+])$ & + & $+(+)$ & $+(+)$ & + & $+(+)$ \\
\hline Caprate & - & $\mathrm{w}(\mathrm{d})$ & $\mathrm{W}$ & - & $+(+)$ & - & $+(+)$ \\
\hline Adipate & - & $+(+)$ & + & $+(+)$ & $+(+)$ & - & $+(+)$ \\
\hline Citrate & + & $+(+)$ & + & $+\dagger$ & $+(+)$ & + & $+(+)$ \\
\hline Phenylacetate & + & $+(\mathrm{d})$ & + & $+(+)$ & $+(+)$ & + & $+(+)$ \\
\hline Malonate utilization & $\mathrm{w}$ & + & + & + & - & + & + \\
\hline Acetamide utilization & + & - & + & - & - & - & + \\
\hline Acid from xylose & - & $-(-)$ & - & $-(-)$ & $-(-)$ & - & $+(+)$ \\
\hline
\end{tabular}

${ }^{\star}$ Reported as positive by Busse \& Auling (2005).

$\dagger$ According to Yabuuchi et al. (1998), A. piechaudii is not able to grow with citrate.

using a $10 \mathrm{~Hz}$ nitrogen laser operating at $337 \mathrm{~nm}$. At least five spectrum accumulations involving 100 laser shots were acquired from each sample spot. External mass spectrum calibration was carried out applying the $[\mathrm{M}+\mathrm{H}]^{+}$and $[\mathrm{M}+2 \mathrm{H}]^{2+}$ molecular peaks of lysozyme. Software FlexControl 1.1 and Xtof 5.1.5 was used for spectrum acquisition and evaluation, respectively. The MALDI-TOF MS mass profile of intact cells was useful for differentiating strain $\mathrm{B}_{2}{ }^{\mathrm{T}}$ from the type strains of other Achromobacter species (see Fig. 2 and Supplementary Table S4). The presence of single peaks at $\mathrm{m} / \mathrm{z} 6210,7086,8928,9972$ and 12626 allowed good discrimination of $\mathrm{B}^{\mathrm{T}}$ from the other Achromobacter strains examined.

Automated ribotyping was performed using cells of Achromobacter type strains cultivated for $24 \mathrm{~h}$ at $30{ }^{\circ} \mathrm{C}$ on Columbia agar base (Oxoid) supplemented with $5 \%$ sheep blood, EcoRI restriction enzyme and a RiboPrinter microbial characterization system (DuPont Qualicon), in accordance with the protocol provided by the manufacturer. The ribopatterns obtained were normalized, automatically categorized into ribogroups and analysed according to Švec \& Sedláček (2008). Automated ribotyping with EcoRI generated bands ranging from 1.2 to $50 \mathrm{kbp}$ and separated all seven analysed strains into different ribogroups. Identification using the RiboExplorer software assigned only the strains of A. piechaudii, A. xylosoxidans and A. denitrificans correctly to the species level. Strain $B 2^{\mathrm{T}}$ and the remaining three type strains were not identified. Achromobacter species revealed great heterogeneity in ribopatterns (Fig. 3), and strain $\mathrm{B} 2^{\mathrm{T}}$ was distinguished from the other Achromobacter type strains.

Although 16S rRNA gene sequence analysis did not provide the resolution necessary to differentiate strain $\mathrm{B}^{\mathrm{T}}$ clearly, distinction of strain $\mathrm{B}^{\mathrm{T}}$ from the type strains of other Achromobacter species could be achieved definitively by DNA-DNA hybridization, MALDI-TOF MS and ribotyping analyses. Its capabilities for acetamide utilization, nitrite reduction and assimilation of gluconate (weakly) as a carbon source for growth together with its inability to assimilate adipate or caprate and to produce acid from xylose allowed the differentiation of strain $\mathrm{B} 2^{\mathrm{T}}$ from the type strains of other Achromobacter species. Based on genotypic, phylogenetic, phenotypic and chemotaxonomic analyses, we conclude that strain $\mathrm{B} 2^{\mathrm{T}}$ represents a novel 
Table 2. CFA profiles of strain $B 2^{\top}$ and type strains of Achromobacter species

Strains: 1 , strain $\mathrm{B}^{\mathrm{T}} ; 2$, A. denitrificans CCUG $407^{\mathrm{T}} ; 3$, A. insolitus CCUG $47057^{\mathrm{T}}$; 4, A. piechaudii CCUG $724^{\mathrm{T}} ; 5$, A. spanius CCUG $47062^{\mathrm{T}} ; 6$, A. ruhlandii CCUG $57103^{\mathrm{T}} ; 7$, A. xylosoxidans CCUG $56438^{\mathrm{T}}$. - , Not detected. Data are percentages of total fatty acids and were obtained in this study.

\begin{tabular}{|c|c|c|c|c|c|c|c|}
\hline Fatty acid & 1 & 2 & 3 & 4 & 5 & 6 & 7 \\
\hline $\mathrm{C}_{9: 0} 3-\mathrm{OH}$ & - & 0.6 & - & - & - & - & - \\
\hline $\mathrm{C}_{12: 0}$ aldehyde & 0.5 & - & - & - & - & - & 0.2 \\
\hline $\mathrm{C}_{12: 0}$ & 1.0 & 1.6 & 1.3 & 0.9 & 1.3 & 0.6 & 0.5 \\
\hline $\mathrm{C}_{12: 0} 2-\mathrm{OH}$ & 2.2 & 2.7 & 2.9 & 2.3 & 1.9 & 2.5 & 2.8 \\
\hline $\mathrm{C}_{12: 0} 3-\mathrm{OH}$ & - & - & - & 0.3 & 0.4 & - & - \\
\hline $\mathrm{C}_{14: 0}$ & 4.9 & 5.9 & 5.2 & 5.7 & 3.0 & 1.7 & 1.2 \\
\hline $\mathrm{C}_{15: 1} \omega 6 c$ & - & 0.5 & - & 0.3 & 0.5 & - & - \\
\hline $\mathrm{C}_{15: 0}$ & - & 0.7 & 1.3 & 0.6 & 0.7 & - & - \\
\hline $\mathrm{C}_{14: 0} 2-\mathrm{OH}$ & - & - & - & - & - & 2.8 & 3.1 \\
\hline $\mathrm{C}_{14: 0} 3-\mathrm{OH} /$ iso- $\mathrm{C}_{16: 1} \mathrm{I}$ & 5.5 & 7.7 & 6.7 & 7.0 & 3.7 & 6.6 & 6.5 \\
\hline $\mathrm{C}_{16: 1} \omega 7 c$ & 25.3 & 21.9 & 26.9 & 12.8 & 35.8 & 22.2 & 14.8 \\
\hline $\mathrm{C}_{16: 0}$ & 33.6 & 30.7 & 31.5 & 34.3 & 33.2 & 37.2 & 41.0 \\
\hline $\mathrm{C}_{17: 0}$ cyclo & 16.9 & 19.9 & 14.7 & 29.8 & 5.9 & 19.3 & 24.1 \\
\hline $\mathrm{C}_{17: 0}$ & 0.6 & 0.7 & 0.7 & 0.6 & 1.2 & 0.6 & 0.5 \\
\hline $\mathrm{C}_{16: 0} 2-\mathrm{OH}$ & - & - & - & - & 0.4 & 0.6 & 0.6 \\
\hline $\mathrm{C}_{16: 0} 3-\mathrm{OH}$ & - & 0.3 & 0.3 & - & - & - & - \\
\hline $\begin{array}{l}\mathrm{C}_{18: 2} \omega 6,9 \mathrm{c} / \text { anteiso- } \\
\mathrm{C}_{18: 0}\end{array}$ & - & - & - & 0.8 & 0.6 & - & - \\
\hline $\mathrm{C}_{18: 1} \omega 7 c / \omega 12 t / \omega 9 t$ & 8.6 & 5.5 & 7.1 & 2.5 & 8.1 & 4.5 & 2.8 \\
\hline $\mathrm{C}_{18: 0}$ & 1.1 & 0.7 & 1.1 & 0.9 & 1.5 & 1.5 & 1.5 \\
\hline iso- $\mathrm{C}_{19: 0}$ & - & - & - & 0.2 & - & - & - \\
\hline Unidentified & - & - & 0.4 & 0.5 & 2.0 & - & - \\
\hline
\end{tabular}

species in the genus Achromobacter, for which the name Achromobacter marplatensis sp. nov. is proposed.

\section{Description of Achromobacter marplatensis sp. nov.}

Achromobacter marplatensis (mar.pla.ten'sis. N.L. masc. adj. marplatensis pertaining to Mar del Plata, the Argentinian city where the type strain was isolated).

Motile, small rod-shaped, Gram-negative bacterium, 0.5$1 \mu \mathrm{m}$ long, able to grow at $15-40{ }^{\circ} \mathrm{C}$. Unable to grow at $6.5 \% \mathrm{NaCl}$. Asaccharolytic. Resistant to kanamycin and sensitive to amoxicillin, ampicillin and carbenicillin (at $30 \mu \mathrm{g} \mathrm{ml}^{-1}$ ). Grows on MacConkey agar. Positive for oxidase, leucine arylamidase, alkaline and acid phosphatase, phosphoamidase and catalase activities and tyrosine hydrolysis. Negative for activities of amylase, arginine dihydrolase, lysine and ornithine decarboxylases, C4 esterase, C8 esterase lipase, C14 lipase, valine arylamidase, cystine arylamidase, trypsin, $\alpha$-chymotrypsin, $\alpha$-galactosidase, $\beta$-galactosidase, $\beta$ glucuronidase, $\alpha$-glucosidase, $\beta$-glucosidase, $N$-acetyl- $\beta$ glucosaminidase, $\alpha$-mannosidase, urease, tryptophan deaminase and $\alpha$-fucosidase. Able to assimilate malate, citrate and phenylacetate and to assimilate gluconate weakly. Capable of nitrate and nitrite reduction. Tests for the Voges-Proskauer reaction and indole production are negative. Unable to grow on inositol, sorbitol, rhamnose, sucrose, melibiose, amygdalin, glucose, $p$-nitrophenyl $\beta$-Dgalactopyranoside, arabinose, mannose, mannitol, $\mathrm{N}$-acetylglucosamine, maltose, caprate, arginine, King's media A and $\mathrm{B}, \alpha-(+)$-D-glucose, $\beta$ - $(+)$-D-fructose, $(+)$-D-galactose, $(+)$-trehalose, $(+)$-D-mannose, $(+)$-L-sorbose, $(+)$ melibiose, $(+)$-raffinose, maltotriose, lactose, lactulose,

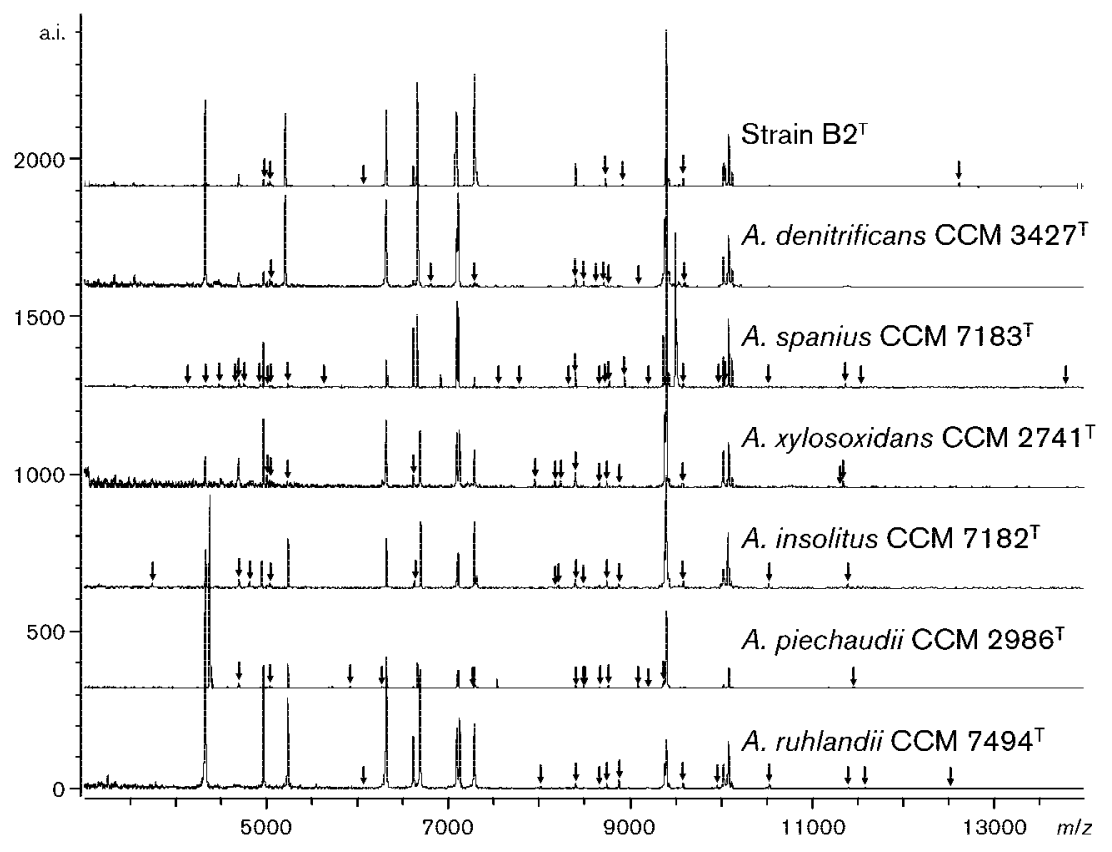

Fig. 2. Profiles of strain $B 2^{\top}$ and the type strains of Achromobacter species based on characteristic peaks obtained by intact cell MALDI-TOF MS. Peaks with relatively low intensities are highlighted with arrows. More details are given in Supplementary Table S4. 


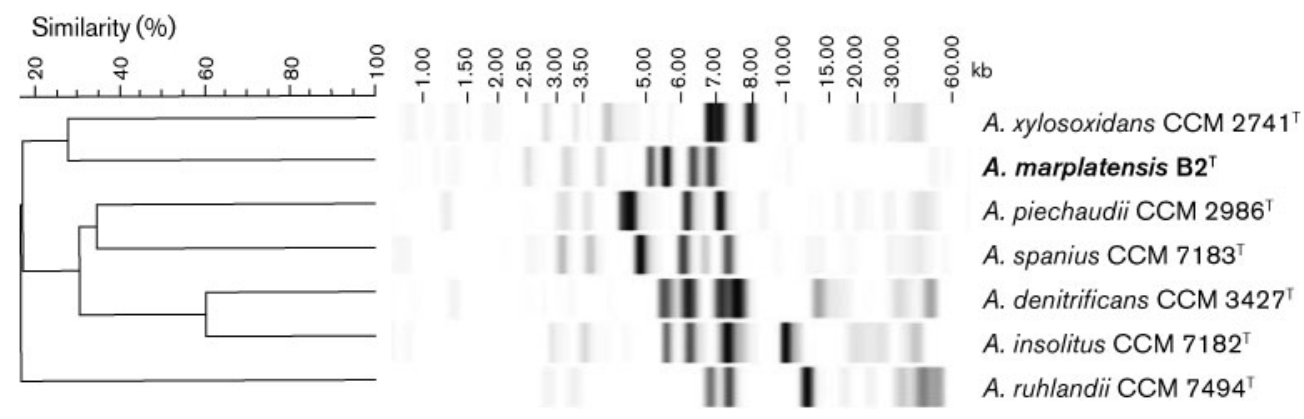

Fig. 3. Dendrogram based on cluster analysis of $E c o R$ ribotype patterns obtained by automated ribotyping with the RiboPrinter microbial characterization system. The dendrogram was calculated with Pearson's correlation coefficient, using the UPGMA clustering method ( $r$ is expressed for convenience as percentage similarity).

1-O-methyl $\beta$-galactopyranoside, 1-O-methyl $\alpha$-galactopyranoside, $(+)$-cellobiose and gentiobiose. Does not utilize 1$O$-methyl $\beta$-D-glucopyranoside, (-)-D-ribose, ( +)-L-arabinose, $(+)$-D-xylose, palatinose, $\alpha$-L-rhamnose, $\alpha-(-)$-Lfucose, (+)-melezitose, (+)-D-arabitol, xylitol, dulcitol, D-tagatose, glycerol, myo-inositol, D-mannitol, maltitol, $(+)$-turanose, D-sorbitol, adonitol, hydroxyquinoline $\beta$ glucuronide, D-lyxose, i-erythritol, 1-O-methyl $\alpha$-D-glucopyranoside, 3-O-methyl D-glucopyranose, D-saccharate, mucate, (+)-L-, (-)-D- and meso-tartrate, (+)-D- and $(-)$-L-malate, cis- and trans-aconitate, tricarballylate, Dglucuronate, D-galacturonate, 2-keto-D-gluconate, 5-keto-Dgluconate, L-tryptophan, $\mathrm{N}$-acetyl-D-glucosamine, D-gluconate, phenylacetate, protocatechuate, $p$-hydroxybenzoate, quinate, gentisate, $m$-hydroxybenzoate, benzoate, 3 -phenylpropionate, $m$-coumarate, trigonelline, betaine, putrescine, DL- $\alpha$-amino-n-butyrate, histamine, DL-lactate, caprylate, Lhistidine, succinate, fumarate, glutarate, DL-glycerate, DL- $\alpha$ amino-n-valerate, ethanolamine, tryptamine, D-glucosamine, itaconate, DL- $\beta$-hydroxybutyrate, L-aspartate, L-proline, $\mathrm{D}$ - and L-alanine, L-serine, malonate, propionate, $\mathrm{L}$ tyrosine or $\alpha$-ketoglutarate. No hydrolysis of aesculin, Tween 80, gelatin, starch, casein, lecithin, elastin or DNA or production of acid or $\mathrm{H}_{2} \mathrm{~S}$ from triple-sugar-iron agar.

The type strain is $\mathrm{B}^{\mathrm{T}}\left(=\mathrm{CCM} 7608^{\mathrm{T}}=\mathrm{CECT} 7342^{\mathrm{T}}\right.$ $=$ CCUG $56371^{\mathrm{T}}$ ), isolated in 2001 from soil in Mar del Plata, Argentina, by selective enrichment with PCP.

\section{Acknowledgements}

This research was supported by Agencia-Pict, Argentina (grant 1303246), and the National University of Mar del Plata. The work of M.G., A. B. and J.L. was supported by the Pla Balear de Recerca i Desenvolupament Tecnologic de les Illes Balears (PRIB). The MALDI-TOF MS and ribotyping analyses were supported by projects of the Ministry of Education, Youth and Sport of the Czech Republic (MSM0021622415, MSM0021622413 and MSM0021622416). Support from the Universitat de les Illes Balears, Institut Mediterrani d'Estudis Avançats (CSIC-UIB), Masaryk University and North Carolina State University is greatly appreciated. The authors acknowledge the technical expertise of the CCUG staff for CFA analyses.

\section{References}

Altschul, S. F., Gish, W., Miller, W., Myers, E. W. \& Lipman, D. J. (1990). Basic local alignment search tool. J Mol Biol 215, 403-410.

Barrow, G. I. \& Feltham, R. K. A. (editors) (1993). Cowan and Steel's Manual for the Identification of Medical Bacteria, 3rd edn. Cambridge: Cambridge University Press.

Busse, H. J. \& Auling, G. (2005). Genus II Achromobacter Yabuuchi and Yano 1981, 477 ${ }^{\mathrm{VP}}$ emend. Yabuuchi, Kawamura, Kosako and Ezaki 1998a, 1083. In Bergey's Manual of Systematic Bacteriology, 2nd edn, vol. 2C, pp. 658-662. Edited by D. J. Brenner, N. R. Krieg, G. M. Garrity, J. T. Staley, D. R. Boone, P. De Vos, M. Goodfellow, F. A. Rainey \& K. H. Schleifer. New York: Springer.

Coenye, T., Vancanneyt, M., Falsen, E., Swings, J. \& Vandamme, P. (2003a). Achromobacter insolitus sp. nov. and Achromobacter spanius sp. nov., from human clinical samples. Int J Syst Evol Microbiol 53, 1819-1824.

Coenye, T., Vancanneyt, M., Cnockaert, M. C., Falsen, E., Swings, J. \& Vandamme, P. (2003b). Kerstersia gyiorum gen. nov., sp. nov., a novel Alcaligenes faecalis-like organism isolated from human clinical samples, and reclassification of Alcaligenes denitrificans Rüger and Tan 1983 as Achromobacter denitrificans comb. nov. Int J Syst Evol Microbiol 53, 1825-1831.

Felsenstein, J. (1989). PHYLIP - phylogeny inference package (version 3.2). Cladistics 5, 164-166.

Gomila, M., Gascó, J., Busquets, A., Gil, J., Bernabeu, R., Buades, J. M. \& Lalucat, J. (2005). Identification of culturable bacteria present in haemodialysis water and fluid. FEMS Microbiol Ecol 52, 101-114.

Jukes, T. H. \& Cantor, C. R. (1969). Evolution of protein molecules. In Mammalian Protein Metabolism, vol. 3, pp. 21-132. Edited by $\mathrm{H}$. N. Munro. New York: Academic Press.

Kiredjian, M., Holmes, B., Kersters, K., Guilvout, I. \& De Ley, J. (1986). Alcaligenes piechaudii, a new species from human clinical specimens and the environment. Int J Syst Bacteriol 36, 282-287.

Lee, S. G., Yoon, B. D., Park, Y. H. \& Oh, H. M. (1998). Isolation of a novel pentachlorophenol-degrading bacterium, Pseudomonas sp. Bu34. J Appl Microbiol 85, 1-8.

Litchfield, C. D. \& Rao, M. (1998). Pentachlorophenol biodegradation: laboratory and field studies. In Biological Treatment of Hazardous Wastes, pp. 271-301. Edited by G. A. Lewandowski \& L. J. DeFilippi. New York: Wiley.

Marmur, J. (1961). A procedure for the isolation of DNA from microorganisms. J Mol Biol 3, 208-218. 
Murialdo, S. E., Fenoglio, R., Haure, P. M. \& González, J. F. (2003). Degradation of phenol and chlorophenols by mixed and pure cultures. Water SA 29, 457-463.

Page, R. D. M. (1996). TreeView: an application to display phylogenetic trees on personal computers. Comput Appl Biosci 12, 357-358.

Švec, P. \& Sedláček, I. (2008). Characterization of Lactococcus lactis subsp. lactis isolated from surface waters. Folia Microbiol (Praha) 53, 53-56.

Thompson, J. D., Gibson, T. J., Plewniak, F., Jeanmougin, F. \& Higgins, D. G. (1997). The CLUSTAL_X windows interface: flexible strategies for multiple sequence alignment aided by quality analysis tools. Nucleic Acids Res 25, 4876-4882.

Tiirola, M. A., Männistö, M. K., Puhakka, J. A. \& Kulomaa, M. S. (2002). Isolation and characterization of Novosphingobium sp. strain MT1, a dominant polychlorophenol-degrading strain in a groundwater bioremediation system. Appl Environ Microbiol 68, 173-180.
Tvrzová, L., Schumann, P., Spröer, C., Sedláček, I., Pácová, Z., Šedo, O., Zdráhal, Z., Steffen, M. \& Lang, E. (2006). Pseudomonas moraviensis sp. nov. and Pseudomonas vranovensis sp. nov., soil bacteria isolated on nitroaromatic compounds, and emended description of Pseudomonas asplenii. Int J Syst Evol Microbiol 56, 2657-2663.

Yabuuchi, E., Kawamura, Y., Kosako, Y. \& Ezaki, T. (1998). Emendation of genus Achromobacter and Achromobacter xylosoxidans (Yabuuchi and Yano) and proposal of Achromobacter ruhlandii (Packer and Vishniac) comb. nov., Achromobacter piechaudii (Kiredjian et al.) comb. nov., and Achromobacter xylosoxidans subsp. denitrificans (Rüger and Tan) comb. nov. Microbiol Immunol 42, 429438.

Ziemke, F., Höfle, M. G., Lalucat, J. \& Rosselló-Mora, R. (1998). Reclassification of Shewanella putrefaciens Owen's genomic group II as Shewanella baltica sp. nov. Int J Syst Bacteriol 48, 179186. 